\title{
Practices and Challenges of Tourism Product Development: Evidence from Choke Mountain and Its Environs, Amhara National Regional State
}

\author{
DAWIT TILAHUN BEKALU
}

\begin{abstract}
The current study is about assessing the practices and challenges of tourism product development evidence from Choke Mountains and its environment. Qualitative research approach has been adopted in the study. Purposive sampling techniques were employed to select key informants. 13 participants were interviewed, and two focus groups were held. The researcher conducted face to face interview by using both structured and semi structured interview questions. With respect to data sources, both primary and secondary data sources were utilized. Interview, focus group discussion and field observation were main data gathering instruments used to collect data for this study. As far as data analysis is concerned, structured narrative analysis techniques were applied. With respect to the result researcher found that Choke Mountain is rich in natural, cultural and historical tourism potential. This study proved that the practice of tourism product development is so limited and need the involvement of all respective stockholders. The other finding of this study indicts that overgrazing, deforestation, illegal community settlement, unlimited use of lands for farming purpose and lack of educated human resource are the major challenges that bottlenecked for practices of tourism product development in the area. The current study is expected to benefit local communities, local \& regional government and tourism service providers finally it provides a contribution in the field of research and researcher can use this work as reference.
\end{abstract}

Keywords:Practices, Challenges, Tourism Product Development, Coke Mountain, Amhara Regional State, Ethiopia

DOI: $10.7176 / \mathrm{JTHS} / 60-02$

Publication date: January $31^{\text {st }} 2022$

\section{Introduction}

According to UNWTO (2010) product development is the creation of products with new or different characteristics that offer new or additional benefits to the customer. Product development may involve modification of an existing product on its presentation, or formulation of an entirely new product that satisfies a newly defined customer want or market niche.

As many scholars agree that today tourism industry has become one of the most important factors in gross domestic product (GDP) contribution worldwide. It plays a significant role in socio-economic development of nations. It is recognized that most of the developing countries now generate economic benefits through tourism industry. In the past, governments have been unwereing to invest in tourism development, but in this modern age the situation has changed (World Bank, 2017). For instance, according to WTTC (2017) report indicates in2017 the direct contribution of Travel \& Tourism to GDP was USD 2,570.1bn (3.2\% of total GDP), and is forecasted to rise by $4.0 \%$ in 2018, and total contribution of Travel \& Tourism to GDP was USD8,272.3bn (10.4\% of GDP) in 2017 and is forecast to rise by $4.0 \%$ in 2018 .

As a report of world tourism and travel council indicates that in 2017 Travel \& Tourism directly supported $118,454,000$ jobs ( $3.8 \%$ of total employment). This is expected to rise by $2.4 \%$ in 2018 and the total contribution of Travel \& Tourism to employment, including jobs indirectly supported by the industry, was $9.9 \%$ of total employment $(313,221,000$ jobs $)$ and this is expected to rise by $3.0 \%$ in 2018 to $322,666,000$ jobs.

Also, tourism in 2017 visitor exports generated USD1,494.2bn (6.5\% of total exports) in 2017 and this is forecasted to grow by $3.9 \%$ in 2018.Again Travel \& Tourism investment in 2017 was USD882.4bn, or $4.5 \%$ of total investment.

In Ethiopia, tourism up to recent year has not been seriously considered in poverty reduction strategies of improving the life of the people across the nations. Tourism development has often been focused at the macro level, on international promotion, attracting inward investment, major hotel and resort development sand on national and regional master planning.

In recent year there is an indication as the government of Ethiopia has given an emphasis for tourism development and gradually tourism has become one major sector in the country.

For instance, as report of WTTC indicates, Tourism in 2017, the total contribution of Travel \& Tourism to employment, including jobs indirectly supported by the industry was $6.1 \%$ of total employment $(1,538,000$ jobs $)$ and this is expected to rise by $1.7 \%$ in 2018 to $1,565,000$ jobs, Visitor exports generated ETB50,447.7mn (USD2,108.0mn), 35.2\% of total exports in 2017 and This is forecast to grow by $6.6 \%$ in 2018 , and also Travel \& Tourism investment in 2017 was ETB18,490.3mn, 2.4\% of total investment (USD772.6mn and it were rise by $5.8 \%$ 
in 2018, Tourism may have more contribution of economically, socially, culturally and environmentally if, the nation encourages and exercise tourism product development.(WTTC,2017).

When come to tourism product development can be defined in many ways: according to NNWTO at one extreme, it can be seen as embracing all elements with which the visitor to a destination comes into contact, including infrastructure (e.g. transport, utilities), the service personnel, places of lodging, attractions and activities, facilities and amenities; while, at the other extreme, Tourism Product Development can be defined as comprising only those attractions, activities and facilities that are specifically provided for the visitor.

In this study the definition of new tourism product development is the process by which the tourism resources like natural, cultural and historical of a destination are formed to meet the requirements of international and domestic customers and to enhance visitors' experience in the destination.

Ethiopia, a country made up of diverse landscapes and ecosystems, home to an excess of unique creatures, a land of incredible culture, language identity for that reason each year both domestic and international visitors flock to Ethiopia to explore the country 's vast, relatively un spoiled natural areas and to view the associated cultural and historical heritages.

For Ethiopia Tourism sector is growing fast and stands as the third foreign exchange earner, following coffee and oilseeds (Mann, 2006).

For the positive contribution of Tourism in Ethiopia, there are many positive factors such us; Ethiopian Air Lines provides international flights and connections to most parts of the world. Ethiopia is reasonably well connected by international flights and Ethiopian Air Lines has one of the best reputations amongst African national airlines (UNWTO, 2004).

The other contributing factor is that many International organizations have their offices in Addis Ababa and it has Strong effect to improve the images of Ethiopia. The government is committed to use tourism in the fight against poverty and very recently government offer arrival VIZA for all African travelers and the involvement of the private sector, community and donor agencies is growing significantly is also the other factor. All in all, Ethiopia is still untouched country and many tourists recommend visits to Ethiopia (SNV, 2006).

Therefore, the country needs to work the 'development of products to the amount and quality that fits the existing demand, in addition to the existing tourism destination Ethiopia needs to use its potential by exploring the potential resources across a country and needs to change the resources in to meaningful tourist products and attraction.

For instance, Choke Mountain has many potential resources that can be used as a destination for many local and foreign tourists just like other sites of the country. Among the potential resources, the existence of marvelous landscape, the four stepped mountains (Arat Mekeraker in Amharic) and many unique flora and fauna like Gibra and aKeyi Kebero (Ethiopian Wolf), and the cool temperate agro-ecological (Wurch in Amharic) zone are the few.

Therefore, Choke Mountain can contribute for different ecotourism development of the country like Semen and Bale Mountains. The other most remarkable feature of this mountain is the virtual existence of wetland ecosystems ranging from sedge swamp to seasonally flooded grasslands which covered more than $3386 \mathrm{~km} 2$. Out of this figure, seasonal wetlands with high moisture, seasonal wetlands with low moisture, and open water constitutes $3000 \mathrm{~km} 2,340 \mathrm{~km} 2$ and $46 \mathrm{~km} 2$ respectively (Teferi et al. 2010).

The above resource bases of Choke mountain range have national contributions, it provides resources like food, water for drinking and small-scale irrigation, grazing, raw materials for building, and recreational or tourism services. It is also used for the maintenance of ecosystem stability, flood control, habitat for various fauna and flora species, climatic stabilization, and scientific researches and training.

\section{Statement of the problem}

There are archeological, cultural, historical and natural grounds that make Ethiopia unique Getahun\& Dhaliwal, (2017).

And they state that Ethiopia is endowed with rich cultural and abundant natural resources and in terms of history, Ethiopia is a very old country, with over 3,000 years of rich history, so we can understand tourism in Ethiopia has the potential to change and enhance the life of the communities in a verity way because Ethiopia has varied natural, cultural, historical and socio-cultural endowments that can be developed to tourism products which can attract many tourists and generate revenue for the government and the community.

As recent UNWTO (2017) reports indicate that nations around the world especially in Africa in recent years bring in tourism sector for the methods of poverty alleviation because tourism is a wide industry and were has environmental, economic, social and cultural contribution for the country.

Even though Ethiopia has many natural attractions, the country is not benefiting from these sites; the competition in the natural segment of the market is high from the neighboring and other more remote African countries. Nature based tourism is well developed and promoted in the other countries tourism markets, and more than in the case of Ethiopia, i.e. Kenya, Tanzania and South Africa are well developed tourism destinations (Tafesse, 2016). 
Although Ethiopia is known by a variety of cultural, natural, historical and social attractions, the country focuses only on the destinations registered by the UNISCO, like Lalibela, Gondar, Aksum, Semain and on the others well known attractions (Demoz, 2017).

Research of tourism product development is not well researched area in Ethiopia, especially in natural and mountain-based tourism product development and also the destination awareness and destination image is very poor until today (Demoz Arefayne et.al, 2017)

There is also scarce body of literature in the area of tourism product development and the existing body of literatures mainly focused on relates with cultural and historical resources, for instance a recent research conducted by Geremew (2015) focuses on the existing cultural and historical tourism resources in Tigray and Amhara regions, they failed to address natural tourism product development practice as well as challenges.

As research by Sintayehu S. (2015) argues that the major problem of Ethiopian tourism is lack of clear identification of new potential tourism sites in the country rather than highly depend on existing destinations. And he also explains Choke Mountain is endowed with potential tourism resources but the local communities and the region in general are not benefited from the tourism activities due to potential tourism resources were not clearly assessed, identified, recorded, mapped and developed.

The resource potentials should be identified, and/or they have to be developed to actual products which can attract tourists and generate revenue. As many researches touches, the practice and efforts to diversify products is an issue which urge due attention in many newly arising destinations in the country. Tourism product development may need the involvement of different stockholders and a high effort and it is the challenging activity (Sintayehu and Belay, 2015).

Choke Mountain and surrounding have not a well-developed tourist facility and the integration of the stakeholders also fragmented, as no clear data in this regard the researcher is going to assess the actual practice and the challenges to develop tourism products in Choke Mountain and its Environments.

\section{Review of literature}

\section{Product Development}

According to NNWTO, (2010) there are two aspects to define tourism product development the first is explain as it is not an activity undertaken in a vacuum, but it is part of an extensive and inter-linked process and the second is Market research, product development and marketing represent a continuum. The failure to deliver any of these key components was resulted in the destination under-realizing it's potential. Tourism products can be defined differently. In general, a product is any offering that can satisfy a need or want of consumers. It may consist of one or a combination of components, including physical goods, services, experiences, events, persons, places, properties, organizations, information and ideas (Kotler, 2001).

A tourism product includes a combination of those components that contribute to the satisfaction of travelers. Brass (1997) suggests that tourism products can be classified into two major components: attractions and facilities. Attractions are those natural and human-made features and events that stimulate people to visit a destination. Facilities, on the other hand, provide necessities to both residents and tourists, and include roads, railway, airports, parking areas, hospitals, police, water and power services and accommodation.

According to Medlik and Middleton (1973), the mix of destination attractions and facilities together create a set of intangible subjective experiences for tourists known as a tourism product - as far as the tourist is concerned, the product covers the complete experience from the time he leaves home to the time he returns to it, Also From the standpoint of a potential customer considering any form of tourist visit, the product may be defined as a bundle or package of tangible and intangible components, based on activity at a destination).

According to Middleton and Clarke (2001) the tourist product means customers value, which is the perceived benefits provided to meet the customers' needs and wants, quality of service received, and the value for money. The tourist product is fundamentally a complex human experience (Gunn 1988), which is an output of a production process, where the tourist utilizes the facilities and services to generate the final output, experience. Value is added in each stage of the production process and the consumer is an integral part of the process (Smith1994).

\section{Component of the specific tourist product}

From customers benefit point of view what businesses of all types offer for sale, Levitt 's classic statement is concise: People do not buy products, they buy the expectation of benefits. It is the benefits that are the product '(Levitt, 1969). Developing this point, Kotler noted the customer is looking for particular utilities. Existing products are only a current way of packaging those utilities. The company must be aware of all the ways in which customers can gain the sought satisfaction (Kotler, 1976).

The tourist product is fundamentally a complex human experience, which is an output of a production process, where the tourist utilizes the facilities and services to generate the final output, experience (Smith, 1994, p. 590591). Value is added in each stage of the production process and the consumer is an integral part of the process (Smith, 1994). The experience is a customer outcome, which, in the eyes of the customer, is associated with added 
value and quality.

This outcome is created and interpreted during the customer process, which have been developed and organized by the service company (Edvardsson \& Olsson, 1999)

\section{New product development-a product formulation view}

To stay ahead of the competition, proactive tourism enterprises must constantly look for new product innovations. The traditional product life cycle theory indicates that typically products were having stages of growth, maturity, saturation and decline in sales and profits. This theoretical model seems to hold true also for tourist products, which means that the question of product development and new- product innovations is important in tourism companies.

It is sometimes difficult to define what is meant by a new product. Improvements to an existing product can render that product so new as to make it seen by prospective purchasers as a genuinely new product, and if an existing product is launched to a new market or to other purposes, that product is also new for the customer.

The need for new-product development arises from the customer needs: in most of the cases the existing customers need new experiences. The marketing strategy and the promotion budgets should be modest: EOMs should concentrate in answering inquires rather than looking for new clients. The word-of-mouth promotion as well as the loyalty of existing customers can direct strategies to service development (introduce new products to present customers) and market penetration (modification of existing products for present customers). Market development (repositioning present products to attract new markets) can be considered and later practiced in way it is directed to target customers (Kotler, 2003).

According to Darko (2011) stakeholders approach brings qualitative and quantitative improvement in tourism supply. It improves tourism consumption and visitor experience practices and the wellbeing of protected areas. The practice of smooth interaction among communities, tourism operators and policy makers would be necessary to achieve sustainable tourism development. It enhances the protection of heritages and other natural and cultural tourism products in the destination. Besides, coordination among stakeholders contributes a lot to promote sustainable tourism development in the destinations. (Caffyn\&Jobbins, 2003).

Mahdayani (2011) conducted a study at Khaoyai National Park in Thailand and asserted that stakeholders are engines in sustainable tourism developments. They are expected to create conducive environment for the visitors.

Furthermore, UNWTO (2005), the term stakeholders in tourism development includes the following key players: 1) Local governments with specific competence in tourism matters 2) Tourism establishments and tourism business operators, including their associations 3) Tourism employees, tourism professionals and tourism consultants 4) Tourism education and training centers 5) Host communities at tourism destinations through their representatives

\section{METHODOLOGY OF THE STUDY \\ Description area of the study}

As description from Amhara regional state government, Choke Mountain is found in East Gojjam Zone, Amhara regional state. The catchment area of Choke Mountain covers more than nine woreda as it is seen in the map. The area is found $333 \mathrm{~km}$ far from the capital city of Addis Ababa and $38 \mathrm{~km}$ far from the Zone capital of Debre Markos and $11 \mathrm{~km}$ from the woreda town of Robe Gebeya. The mountain lies between $10^{\circ} 420^{\prime} \mathrm{N}$ latitude and $372^{\circ} 52^{\prime} \mathrm{E}$ longitude. The area has different topographical features ranging from 2800 to 4088 mails, which includes plateau, deep incised valleys, escarpments, plains, and gorges. Choke Mountain region is found within six climatic zones. These are; Upper Kola, Lower Weyna Dega, Upper Weyna Dega, Lower Dega, Upper Dega and Wurch. The average temperature is between $0^{\circ} \mathrm{C}$ to $30^{\circ} \mathrm{C}$ and gets 200 to $2200 \mathrm{~mm}$ rainfall (Belay S. et.al, 2013).

To achieve the research objective of this study, exploratory research design has been utilized to assess and explore the practice and challenges of new tourist product development in Choke Mountain and its environs. According to Polis\& Beck 2004, exploratory research used to investigate a problem which is not clearly defined. Such a research is usually carried out when the problem is at a preliminary stage. The study employed qualitative types of research, according to (Cameron, 2009), qualitative research is conducted in a natural setting and involves a process of building a complex and holistic picture of the phenomenon of interest. Since one of the major reasons for doing qualitative research is to become more experienced with the phenomenon under study and to investigate complex and sensitive issues. On the other hand, this can further be used to identify factors and challenges of tourism product development. The populations of the study are from the east Gojjam Zone cultural and tourism officers, Tourism experts in Debre Markos city, Debre Markos University, Senan Woreda culture and tourism office and Senan woreda community. In this research non-probability sampling technique is applied. Respondents are purposively selected based on their previous experience, position and educational background on the issue, in order to get in depth information about the research problem at hand. To make a far-reaching statement, data also collected from two focus group discussion (FGD and 15 fifteen interviews based on the principle of data saturation and the respondents from the local communities were also selected purposely. To get a rich information and best 
research result the researcher has been used both primary and secondary data relate to the study through interview, FGD and observation.

This researcher analyzed the collected data through Narrative analysis and also researcher used the direct quotation of respondents including the organization / where they came. This method involves the reformulation of stories presented by respondents taking into account context of each case and different experiences of each respondent. To enhance the instruments validity, the research instruments and the data has been reviewed by the experts in the field of research. Based on the reviewers' comments the unclear and obscure questions were revised and the complex items reworded and removed. And also the researcher has checked the results and interpretations and took back to the participants in order to be confirmed and validated.

\section{Result and discussion}

\subsection{Demographic Characteristics of Respondents}

The respondents were selected from different departments purposely because of their role in tourism and the area they represent.

In addition to 15 interviewee there held two FGDs in Debre Markos city and Senan woreda with the member of five and six respectively.

The FGD participants in Debre Markos were selected purposely from East Gojjam culture and tourism office, Debre Markos University choke mountain conservation project and Debre Markos city culture and tourism office. The FGD participants held in Senan woreda also selected purposely from Senan woreda culture and tourism office, local community representative, clergies and elders.

\subsection{The potential tourism resources of Choke Mountain and its environments}

The potential tourism attractions were viewed in terms of examining and identifying essential aspect of natural, cultural and historical tourism resources. In addition to the geographical feature the area has unique biodiversity resources which include plant, animal, and bird species. The cultural and historical values of Choke Mountains also can be tourist attractions.

\subsubsection{Nature based tourism resources of Choke Mountain and its environs}

Based on the respondents other data the nature-based tourism resources of Choke Mountains are preferred as it has diverse range of geographical features like land forms, water basin, gorges, cliff, native biological diversity and other spectacular views. The researcher found the following nature based tourism resources in choke mountain areas

\section{1) The four stepped mountain chains (Arat Mekerakir)}

This remarkable landscape is found in Senan woreda in the south west of the mountain which is called Arat Mekerakir. The four stepped mountain ranges are lined in south West to North-West. Based on the local, the name Arat Mekerakir is given because the number of the mountain chains are four in number.

And as says from the key informant respondents, each level of mountain has a local name based on the mountain size and shape in addition to its height.

"The first mountain range is "Enat Amba" which means a mother hill due to its big size from all of the hills. The second peak is "Gemsi Amba" which means a fractioned hill. It is the second nearest hill to the gravel road. The third hill is called "Qulit Amba" which means a hill with the shape of a banqueting tool called 'Qulit'. The fourth hill is "Lemat Amba" which means a hill with the shape of traditional meal presenting tool called "Lemat" and this is the furthest hill from the main gravel road".

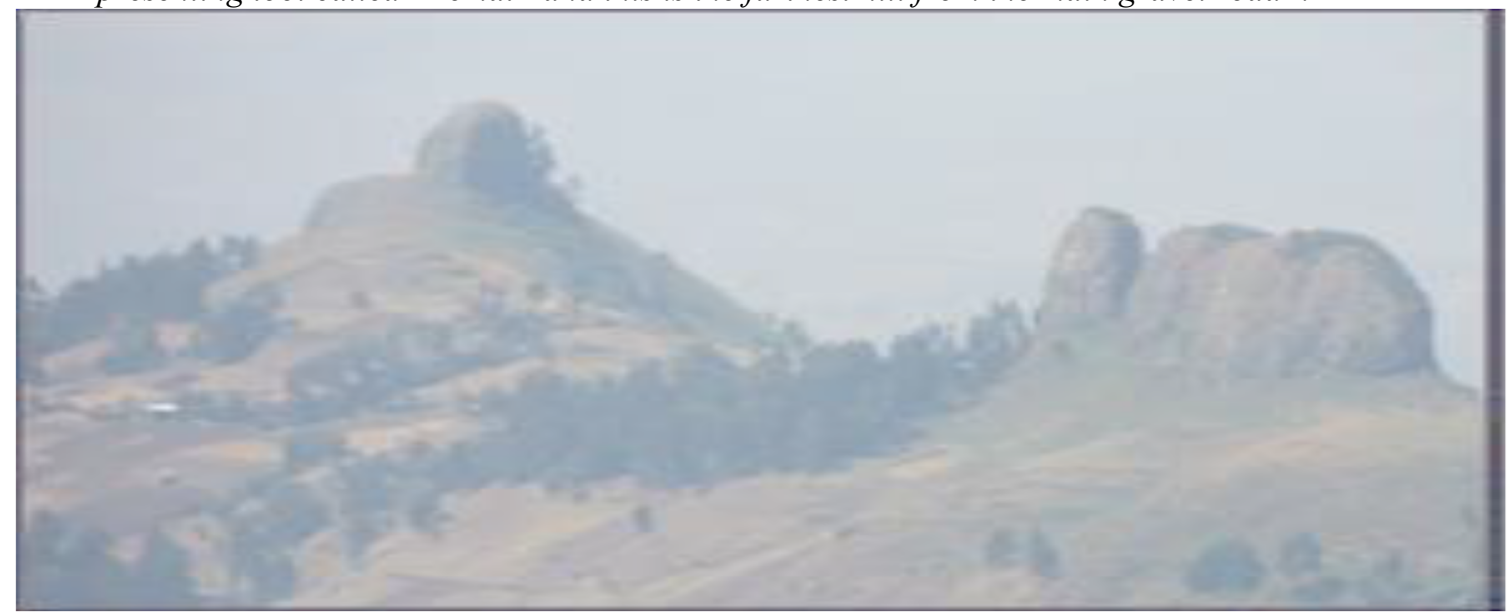

Picture 4.1 Gims and Qulit Amba, photo by Senan woreda culture and tourism office, 2018

With relation to those stepped mountains camping, mountain hiking, trickin and photo touring are possibly the 
perfect tourism activities to visit the four Stepped Mountain (Arat Mekerakir), and similar studies has supported such activities are popular in Semain mountains national parks. The research by Sanjay K. Nepal \& Raymond Chipeniuk (2006) also supports that Mountains, has the great potential to attract tourists with the experience of aforementioned activities

The research also adds that many mountain communities are looking for opportunities to develop their tourism industry and, given global trends in tourism and recreation; it were not be surprising if new mountain destinations are explored and developed. People are continually searching for new forms of recreation and settings for it, and mountains have often provided the 'pleasure grounds'.

2) Molalit cave: this cave one of natural and historical attraction in Choke Mountains which is found in Bebugn woreda in choke mountain Areas.

The cave has an expected height of $150 \mathrm{~m}$ sea level. The exclusive feature of the cave besides its breathtaking view is serving as human shelter since 1902 in the form of progression. Respondents said based on the oral tradition,

"Once upon a time a woman has migrated to this cave before 100 years ago to protect her cattle from epidemic disease. Then after, the local communities totally isolated her from their social ties. As a result of this, the woman had no option other than living within the cave. From that time onwards, she made the cave as permanent house".

As the Says of respondent this Cave is still serving as a home for local communities,

"...Currently, one family with children is living in the cave as a permanent residential. the inside part of the cave has an estimated width of 10-15m, and which is classified in three rooms for family, cattle, sheep and goats similar with other ordinary residential houses".

The researcher found that the applicability of this cave is so great to be developed in to tourist product and the experience of different destination support that caves can be a good tourist attraction.

For instance, we can see the experience of Sof Omer cave in Ethiopia, these types of natural and historical tourism resources are significantly support the area to be a good tourism attraction with having diversified tourism products.

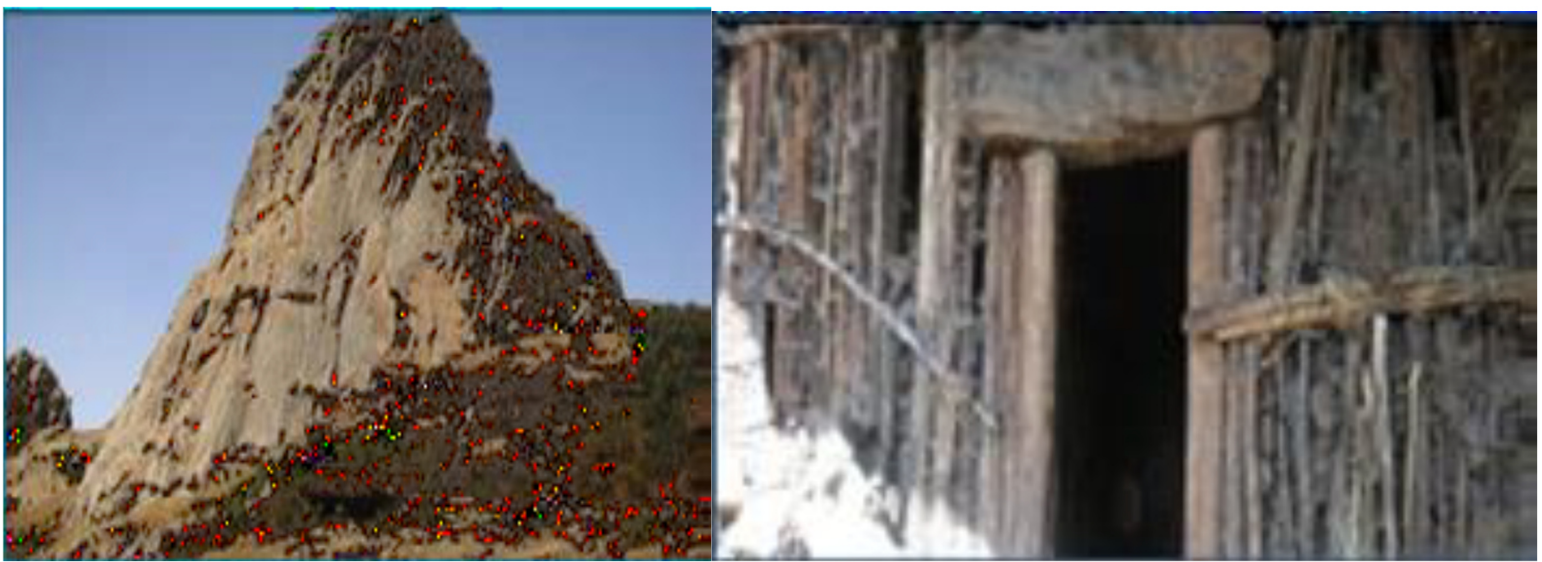

Picture 4.2 Molalit cave and entrance of the house in the cave

3) Aba Jime Forest

After an interview conducted, FGD held and observation the researcher found an interesting forest, after traveling $8 \mathrm{~km}$ from Rob Gebeya with a gravel road, there is a dense eye caching forest named Aba Jime forest which is covers a large area. Asta (Erica arborea) is the dominant plant species. Kosheshila (Acanthus sennii), Nechate (Helichrysum citrispinum), Gibra (Lobelia rhynchopetalum) and Amijja (Hypericum revolutum) plant species are also found. Additionally, the forest is the habitat for many animal species like Bush Pig, Monkey, Jackal, and Hyena are the major.

Having this good forest with biodiversity potential will enhance the tourism activity of the area and it also help the ecosystem of the environment finally it encourages the stockholder to develop different tourism related business in the area finally forests can facilitate the activities of developing in to protected area.

This finding is also supported by Jeffrey D. Kline (2006); and he suggested that National forests likely were having an increasingly significant impact on tourism in communities located near them. As the population continues to grow and become more urban, so do ever-increasing demands for outdoor recreation opportunities. Such increased demands were place growing pressure on National Forests and other public lands to provide the types of non-timber amenities desired by many recreationists.4) Bird species According to the report from East Gojjam zone tourism office and Senan Woreda tourism offices; responses from FGD and interview session in different woreda tourism offices there are about 49 bird species found in afro tropical highland. From these, 16 species are found in Choke Mountain and among 31 globally threatened bird species, endemic Abyssinian Long claw (Macronyx Flavicollis) is also found. As a report from the Senan woreda couture and tourism office in the 
study area 41 bird species are identified in the area. And also the report indicates that Some of the bird species are endemic for Ethiopia such as Abyssinian Long claw, Wattled Ibis, Tick-billed, Raven, White-collared Pigeon, and Black-winged Love bird In different nature-based tourism birds and other natural beauties are the major tourism products that significantly attract the tourists. Due to its suitable environment for varieties of bird species, it has a great potential for the watcher to watch birds. Because the area has over 41 bird species, it could be also an ornithological paradise for bird watchers. Therefore, in tourism having Varity and endemic bird species can be one tourism attraction and help the area to diversify the destination products and also the can make the area very famous by bird watcher.

5) Wildlife species, the offices report also shows in addition to the birds this area is also rich in animal species, there are 16 animal species found in Choke Mountain and its Environments. For instance, the respondent from east Gojjam zone culture and tourism office, tourism promotion experts, The area is rich in animal species. Our report shows that there are morethat 16 animal species in the area like Golden/Common Jackal (Canis aureus), Common Bush Back (Tragelaphus scriptus), Abyssinia Colobus, Common Duiker, Spotted Hyena (Crocutacrocuta), Anubis Baboon (Papio Anubis), Bush Pig (Potamochoerusporcus), and Common Duiker (Sylvicapra grimmia). The researcher found the area rich in both birds and animal species and those are a vital role in tourism development if they are protected, developed and promoted in to tourist products.

This finding also supported by Noel Scott (2014) Wild life tourism is tourism based on encounters with nondomesticated (non-human) animals. These encounters can occur in either the animals' natural environment or in captivity.

And his finding explained such activities in wild life tourism includes activities historically classified as 'non-consumptive', such as viewing, photography and feeding, as well as those that involve killing or capturing animals, particularly hunting (in the terrestrial environment) and recreational fishing (in the aquatic environment). Photo tour is also another activity that can be developed in the vicinity of Choke Mountain. The geographical feature of Choke is broken by numerous spectacular landscapes which are marvelous. Along with the home of many bird, animal and plant species, it creates an opportunity for both domestic and international visitors who appreciate the beauty of nature to experience photo tours.

\section{6) Lake Bahire Giyorgies (the Miracle Lake)}

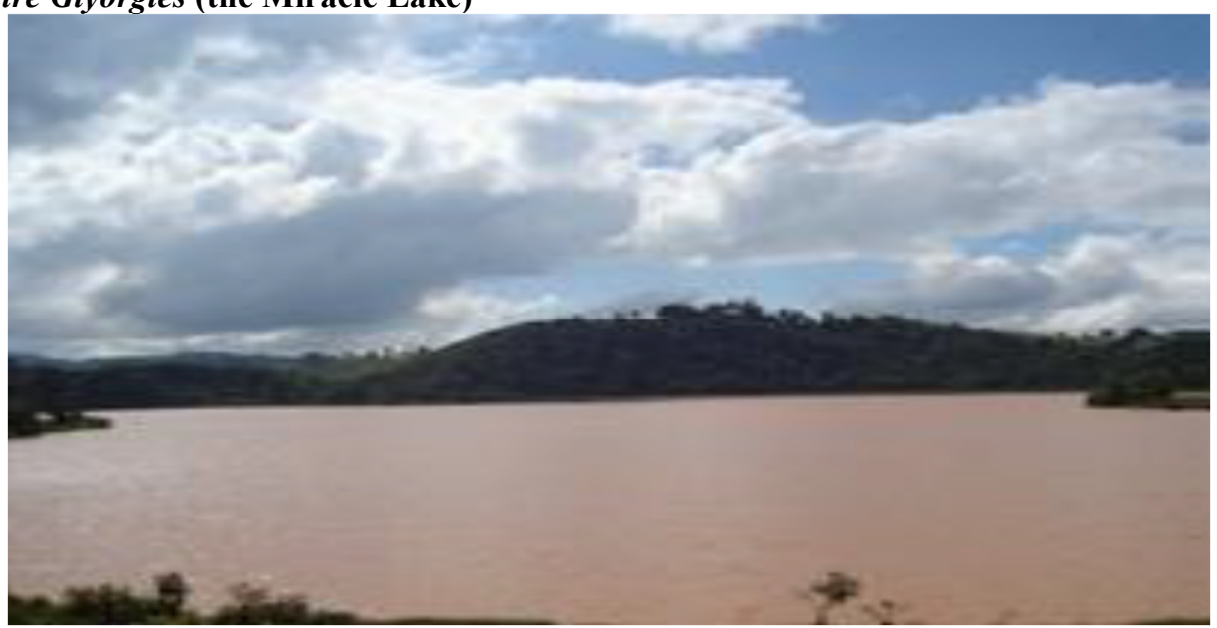

Picture 4.5 Lake Bahire Giyorgies

This bountiful Lake is found in the in the area of Choke mountains and as report from Amhara regional state water and irrigation bureau it covers about 112 hectares and it is the fourth largest lake in Amhara region next to Lake Tana, Lake Estifanos, and Lake Ardibo.

The unique feature of the lake is the so called "Meqa" grass which has islands structure on the surface of the lake. The grass is navigating on the surface of the lake in deferent time and direction by forming island structure and it may empress tourist.

According to the explanation of one key informant,

"... and The Lake has also an attractive looking due to its location in a deep Gorge and which is surrounded by natural forests. Within the forest there are three caves named as cave 1, cave 2, and cave

3 , and on the top of the hill to the south east of the Lake, Giyorgies church is found".

Lake and tourism is interconnected and lakes has a positive effect on the development of tourist flow of an area because, there are many tourist's activities in the lake and this finds directly affiliated with the research of Petric \& Madic (2014), which relay that on water bodies and lakes tourism can be experienced. Also the research shows that the range and opportunity of developing nature based tourism like eco-tourism, national parks, fauna and flora, landscapes, whether conditions and natural beauty including agro tourism. From this perspective Choke Mountain and its environments are riches with natural recourses which meet the criteria and the characteristics to 
be tourism products.

\subsubsection{Culture based tourism resources}

Culture is the best tool to display the unique features of the community and it has multiple value especially in tourism it has a great chance to attract tourists because of Bing unique. The data obtained from focus group discussion showed that Choke Mountain and its environs are much endowed with intact tangible and intangible cultural heritages. According to Ngozi Ezenagu and Iwuagwu Chinonso (2016) Cultural resources are physical features, both natural and man-made, associated with human activity. The man-made resources include objects shaped or created from human actions while natural resources include those physical and animal features used by humans for specific purposes apart from its natural use. Therefore, cultural resources, constitute unique medium through which all people regardless of background can express and distinction themselves from their neighbors. It stood as an evidence of man's existence in the past and today as man's cultural identity. As the product of human culture it embraces man's diverse belief, festivals, traditional architecture and technology, dance, drama, dressing, diet, arts and craft etc. which are the features of any society both past and present. Presently, tourism has become a popular global leisure activity and it is generally thought of as an activity in which individuals explore a culture that is foreign to them for the most part. It is a medium through which foreigners (Tourists) come into contact with other often highly unique cultures. Most times the cultural endowments of a country lure people into tourism. Hence, on a closer look at cultural resources and tourism one would observe that these are indeed complementary. On one hand cultural resources promotes tourism development and tourism on the other showcases and preserves a people's cultural heritage.

The researcher found many cultural and historical evidences that has a potential bing tourism products like monasteries (Dima Giyorgies monastery, Debre Work Mariyam monastery, Washa Giyorgies Filfl Church, and Merto Le Mariyam Monastery), Carts of Agew / Ye Agew Ginb/,the inception rock church of Lalibela / Ye Lalibela Jimir Betekrstian/Church education (Ye Abinet Timhirt) are the major cultuiral and hidtorical attractions that are attracting local torists and have potential to have best destination for both domestic and in ternational tourists if they well documented and promoted.

\subsection{Major challenges of tourism product development in choke mountain areas}

As the current study assessed the area is rich in natural, cultural and historical tourism potential recourses, but still there are not the significant number of tourists and known tourism products in the area and the area has faced different challenges and difficulties to make the area famous in tourism and to develop all the tourism potential in to expected tourism products like to other destinations.

In FGD session after all the arguments of all the participants agrees and identify the following problems and challenges to develop tourism products from all the potential of Choke mountain and its environment.

1) Overgrazing, The communities in Choke and surrounding is well known agricultural activities like farming and rearing of animals and according to East Gojjam agricultural office, there are high number of animals like cattle, ships, goats, horses and donkeys and as the data from agriculture office of East Gojjam the number of animal is estimated number of 400000 animals in and around Choke mountains. And this large number of animals is daily living there and Choke is the only source of food for the animals all round a year. In FGD the researcher found that there is unlimited illegal settlement in the area and the communities and their animals are bringing distraction and problem in the habitant of the mountain areas. In the desiccations, the other major problem is there are no other alternative economic are and the communities' wealth is expressed in terms of having those animals, this makes Choke mountain areas very difficult to protect and develop product in full potential.

2) deforestation, Deforestation and illegal firing is the other dangerous challenge in the area for instance the amazing and eye caching which is found in Senan woreda, and covers more than 68 hectares is victim with this major problem. And the other parts of the mountain which is found in Hulet Eju Enesse woreda and covers more than 5000 hectares also faced this challenges many times in recent years. As a result of deforestation and illegal fairing in many parts of the mountain is coming for the case of endangering different fauna and floras in the mountains. According to the respondents from local community representative, the local communities also frequently experienced deforestation to get farming lands and this is the reason for minimizing different water sources in the mountain. But some of the participants in FGD argues, our life is depending on farming and there is shortage of land in the area, we haven't any alternative rather using the mountain area to support our life. Indeed, Choke Mountains are very rich in fauna, flora and water bodies, but now because of the frequent activities of the local community the biodiversity and ecosystems of the mountain are in endanger conditions. First of all, it requires to know the importance of forests, Forests are critical to the global climate system due to their ability to absorb and store carbon. Carbon loss due to deforestation is estimated to contribute about 17 to $20 \%$ of global greenhouse gas (GHG) emissions (IPCC, 2007). The loss of forest biomass and oxidation of soil organic carbon through slash-and-burn and subsequent land use releases approximately 5.8 Gt CO2 annually into the atmosphere (Nabuurs et al., 2007). Research shows that 
much of this deforestation occurs in tropical forests found in many developing countries and this also affects the tourism development in the area. But it is clear those community activities were adversely affect both natural and cultural resources of the mountain area. And also this may bring the difficulties of tourism product development practice in the area because the tourism product development is manly based on the potential tourism recourses in the area.

3) Poor Tourism Infrastructural Development The researcher understood that, there is a serious problem of shortage in number, type, and quality of tourism infrastructure development. The tourism infrastructure like accommodation establishment, road and transportation, destination facilities and services, and public and institutional supplies are very poor and limited in number. Absence air transport from Addis Ababa to Debre Markos for many business class tourists is aggravating the problem since the rout between is somewhat tiresome. However, tourists want remote and exotic experience. As a says from both woreda and zone level tourism officials, there are inadequate destination facilities and services in choke mountain areas (inadequate shopping facilities and destination signage, limited commercial facilities, limited information communication, banking services and limited public and institution facilities) which are the big challenges for its development. But, research by Madeline M.C. Significantly supports the positive relationship between the infrastructural activities and the development of tourism in the area, this may increase tourist flow, accessibility and as a result high tourist turnover in the area.

4) Poor community awareness The data from interviews showed that the level of community awareness for conservation is very low. Key informant said that, "The mindset of the rural community of Choke Mountain region is not ready for welcoming and accepting both the tourism activity and tourists. This is due to low level of community's awareness, uninformed and old-fashioned". The other key informant adds,

"Consequently, ecosystem of Choke Mountain has been being threatened because of illegal activities of local communities like clearing of forest for construction and fuel wood, expansion of agricultural farming land, and hunting of wild animals".

Most of the rural communities in the area lead subsistent way of life because they are following traditional farming system along with traditional ways of raring of sheep, goat, horse, and cattle. These also have negative impact on the ecosystem and it may bring ecosystem degradation such as soil erosion, water pollution, deforestation, migration, and extinction of wild life, and at the end, Choke Mountain ecosystem is losing its natural beauty. The view of the locals must be taken into consideration so that it was aid attain worthy decision making process and manage resource competently and effectively (WHO, 2002). The professionals in the other pointer has approved that involving the community might contribute to an enhanced decision making, in fact, community participation also has the probability to teach and escalate their responsiveness by being more receptive.Based on a study conducted by Glass (1979) community participation in development were produce greater information exchange between the community and the planners, which can be a significant component to upkeep the government and the proposed development but it needs the extensive program for training and development.A study conducted by Fagence (1977) has explained that community participation is a portion of the democratic system which were permit the locals to express their views on development matters which were affect their lives in the future.

Based on another study by Chekki (1979, cited in James and Blamey, 1999) has elucidated that the participatory democratic is 'all acts of citizen that are intended to influence the behavior of those empowered to make the decisions'. Most of the scholars has propose that community participation process which being a part of democratic system also comprises community's decision making process

Less Administration and Co-ordination Effort of Government

Government has the capacity and the legitimacy to facilitate and coordinate multiple stakeholders to minimize negative impacts (Zhao \& Timothy, 2015). 69

Therefore, effective tourism planning is a prerequisite for successful destination management, one that governments need to take into consideration, specifically when it comes to developing economies (Farmaki et al., 2015). Community based ecotourism, as a logical component of community development, requires effective coordination of the various stakeholders. Governments, the private enterprise, local communities, and NGOs all have vital roles to play in the area of eco-tourism activities in Choke Mountain. Every country (especially the less developed ones) should set up clear guidelines to achieve effective participation of those stakeholders and to achieve the desired ecotourism goals.

Based on the data analyzed from interviews, the various governmental actors in Choke Mountain (at Zonal, Woreda, and Kebele level) have assumed less administration and co-ordination effort for the sustainable development of Choke Mountain and its surroundings. Naturally, Choke Mountain chains have no buffer zones. As a result, there is no clear boundary demarcation among the nearby woreda.

But boundary demarcation for such types of tourism destination is facilitating the development of tourism.

This indicates the gaps in administration work and the nearby woreda as no sense of ownership to protect Choke Mountain from its disruption that highly weakened and undermined the co- ordination and integration effort 
of the actors to ensure sustainable utilization of natural resources.

\subsubsection{Incapability of Financial and Human Resources}

By its nature, tourism sector is more of labor intensive and requires huge investment to develop tourism infrastructure in the destinations (Meguid, no date). Similarly, to develop community-based ecotourism in Choke Mountain, it requires huge investment capital and human resources. But the result revealed in this study is that there is financial incapacity to undertake practical job in the site like tourism resource mapping and inventory, promotion, research and development. Besides, it is difficult to develop tourism infrastructure to facilitate community-based tourism development.

On the other hand, trained manpower in the field of tourism is highly needed to undergo the development projects effectively. 70

However, as it is gained information from key informants and field observation, there are shortages of trained manpower resources in the area. Even though there are ecotourism society groups in different parts of Choke Mountain particularly in Senan and Bebugn woreda, they do not have ecotourism concepts. It is pointed out that these groups are not strong enough to develop ecotourism sites by compromising the environmental, economic, and socio-cultural impacts.

\subsubsection{Destruction of Natural and Manmade Heritage Resources}

Although the area of Choke Mountain has bestowed with natural and manmade heritages, those heritages are now degrading because of poor conservation and protection of heritages as it is discussed above. In light of the naturebased resources, the tangible and intangible cultural heritages are integral elements to develop community-based ecotourism in Choke Mountain and its environs. Nonetheless, in all possible sites, there is poor conservation habit to protect and double the values of the cultural resources. This problem is serious especially in many of churches and monasteries.

Challenge of destination product and service on the statement "destruction of natural resources in destination as challenge", the majority of the respondents disagreed although other scholars have mentioned issues such as over-exploitation, deforestation from firewood harvesting, trampling/soil degradation of the camping sites, plant picking and uprooting by plant collectors, and construction and destruction of unique flora (Gichiah, 2004). These respondents haven't fully realized that the use of nonrenewable energy, the weak protection of natural landscape and environmental resources, unacceptable and the waste disposal systems of the destination development sites are problematic for sustainability.

In general, there is no doubt that in the future a significant number of tourism destinations were face serious global challenges which may adversely affect their profitability, such as climate change.

\subsubsection{The climate change}

As one elder /senior citizen from Senan woreda says,

"...In my age I observe many changes in Choke mountain, it was difficult at the top of the mountain because of its coldness and sometimes there was even the cold 71 and also there was a wide coverage of wet land in the area, I remember if you walk on the wet lands you were feel like jumping on the foam but now it is also diminishing because of climate change and other conservation issues...".

With its close connections to the environment and climate itself, tourism is considered to be a highly climatesensitive economic sector similar to agriculture, insurance, energy, and transportation (Gössling \& Hall 2006, Becken \& Hay 2007, Scott et al. 2008). Climate defines the length and quality of tourism seasons and plays a major role in destination choice and tourist spending. Climate affects a wide range of the environmental resources that are critical attractions for tourism in many destinations and has an important influence on environmental conditions that can deter tourists.

\subsubsection{Absence of tourist facility center}

Besides different natural and cultural tourist attractions a facility is the most important part of tourism development that may attract visitors from different countries. Regarding the dire lack of facilities and services at the destination sites, most of the respondents thought the same. The finding shows that there is lack of facilities and service in these study destination sites that include poor transport or accommodation capacities or a lack of infrastructure (e.g. parking, water facilities, cash withdrawal, restrooms, shade, shelter, sewage, etc.).

Similar results have been observed in previous study (Meskele et al. 2016). Regarding services and facilities expected in the tourist destination sites, including proper internal roads, foot tracks, signage, resting sights, tented camps and standard camping sites with the requisite facilities, these were some of the important facilities needed by tourists but were found to be poor. Lack of facilities (i.e. access, public transport, and accommodation) leads to bottlenecks the destination development (Waveir, et al. 2017).

The facilities poor quality, whether real or perceived, exert a negative impact on the reputation of host countries (Anonymous, 2010). Therefore, government and other stakeholders should give attention to the development of facilities in and around tourist destination sites.

Modern infrastructure is the most important factor to enhance the flow of visitors and benefits for all stakeholders. The development or upgrading of infrastructure such as roads, water, and electricity must be shared 
by both tourists and local people (Frey and George, 2010). With respect the tourist facilities and other related service, almost there is no found any of them in Choke Mountain. Actually there are gravel roads which are cross Choke Mountain in four directions but as the respondents prove that the roads are built with no consideration of tourist attractions in choke areas.

\section{CONCLUSIONS AND RECOMMENDATIONS}

\subsection{Conclusion}

This study ascertained that Choke Mountain and its environs have huge tourism potentials and identified potential tourism resources which consisting of natural, cultural, and historical tourism attractions. Naturally, the area has endowed with spectacular features such as majestic stepped mountain scenery, caves, water bodies, climatic variation, dense forests, and endemic plant, animal and bird species and the like plus to this the area has also rich in terms of cultural and historical aspects like the agricultural activity that the community practiced, the music style they used, the ceremonial events and festivals, and different cultural institutions like Edir, Ekub and Mahiber. In line with this, the area has also an ideal place where both built and living cultural artifacts are attention-grabbing. For example, churches and monasteries along with the religious ceremonies and festivals, church education and other heritages have huge potential tourism resources. In relation to historical tourism resources, Aba Kositer Däjazmach Belay Zeleke and associated 74 attractions (hero's memorial palace, birth place, church, battle fields, and Kuselegnawe Warka) could be augmented with natural and cultural attractions.

As deferent researches show that to make a country more beneficiary from the tourism sector the country should work the identification, mapping and developing the tourism potential in to tourism products. In case of Choke there are many expected diversity activities to use the existing tourism resources but still today choke is untouched destination and it needs the participation of all stakeholders.

Issues of coordination, collaboration and partnership are now at the forefront of much tourism research on finding new solutions to resource management, destination development in tourism product development problems (Madeline, 2010).

Stakeholder is a wide term which may contain the involvement of many interested and responsible bodies, but in case of Choke the supply side of tourism like facilities, accommodation, tour and travel agents, transportation services, tour guides, and even the local communities and promoters are not participating and zonal, woreda and Keble government offices are participated in tourism development.

Stakeholders within the tourism industry undertake various important roles in promoting tourism development for the country but, in case of Choke mountains area there is no a meaningful coordination and collaboration of tourism stakeholder.

Regarding the challenges with tourism product development in Choke mountain areas thee are found different critical problems which mainly affect the development of tourism products in particular and tourism development in general.

As the Coke mountains area are located in rural area and the communities are growing and demanding more lands for agricultural uses due to those and other reasons the main challenge is related with,

Overgrazing, deforestation, illegal community settlement, unlimited use of lands for farming purpose and lack of educated human resource in this regard including climate change, lack of government policy support, poor stakeholder collaboration, communities' awareness towards tourism, un clear boundary embarkation of the Choke mountains as destination, is the major challenges what a researcher found in Choke mountains area.

\subsection{Recommendation}

In this study different natural, cultural and historical tourism potentials of Choke Mountain and its Environs were identified. However, the study also identified different gaps which are the bottleneck to develop tourism products from the potential identified. Therefore, to exploit tourism potentials of the area and to make best tourism destinations with full of attractive tourism products, researcher has suggested the following recommendations.

To use all tourism potential for the development of tourism area and to increase the benefit of government, communities and other stakeholders, first all potential should be developed it to meaningful tourist products.

To make successful tourism product development in the area, need a positive involvement of different stakeholders like government, NGOs, private tourism business enterprises, local communities, Medias and other possible tourism stakeholders of tourism. To make Choke Mountain and its environs for tourist destination, first the potential tourism resources of the area should be well promoted through different promotional tools and it has to have broader awareness creation program for the wider communities towards the tourism resources via awareness creation campaign.

Generally, the researcher has recommended and suggests different ideas for different stockholders. For instance,

\subsubsection{Government}

Involvement in tourism development is widely recognized (Zhao \& Timothy, 2015). As dredge (2010) points out, 
the key function of government is to protect and enhance public interest; a key motivator behind such involvement is the responsibility for controlling and monitoring the scope and pace of tourism development. In addition, tourism is a highly fragmented sector where issues and conflict emerge and intertwine, often unsolvable by the private sector, thus calling for government involvement and also there are issues in choke that needs the involvement of local and regional government like,

1. Boundary demarcation, as Choke Mountain majorly has covered the administration area of more than four woredas. As a result, there is no responsible distinctive body to manage as destination, conservation, development and promotion as destination .so the researcher recommends that the boundary demarcation were facilitate the tourism product development of the area.

2. Road construction, accessibility is the major factor which affects the success of the destinations in terms of tourist arrival. So destination with a easily accessibility invites the development of tourist product development.

3. Creating the awareness of local communities, choke is found in the rural area and the local community mainly manages their life with agricultural activity mainly in choke area and the local community awareness towards tourism still poor so government is expected to give extended trepanning for local communities on the issue how tourism is benefit for them.

4. The other strategic activity is policy formulation, and minimizing the dependency of the local communities on the areas by creating alternative way of energy, work opportunity and other alternative way of life which helps to minimize the negative effect on the natural and cultural resources of the area.

5. To develop and to promote the cultural tourism of the area developing a museum may the best display of the cultural richness of the community and it is one way of promotion so, the researcher has recommended both the local and regional government to have a museum.

6. Finally, both local and regional government is the promotional activities, promotion require a research and a large investment so that it is difficult to promote the destinations by a single body.

\subsubsection{Private business enterprises}

Private business enterprises are the major tourism stakeholder which is facilitating the tourism development in general and tourism product development in particular. And the private business enterprises are expected to do the flowing activities with the collaboration of governments.

Improve and establish different accommodation establishments, private transportation systems should be improved; health centers, electricity,) should be provided in the sites.

Destination facilities and services should also be provided. Tourist information centers, information communication, tour and travel facilities, guiding services, recreational centers, shopping and commercial facilities, billboards and signage, maps and other facilities should be available.

\subsubsection{Local community}

Local communities are a stakeholder and owner of the destination and the community shall participate in the protection and conservation of both cultural and natural attraction which are identified in this research. For example, minimizing the negative effect of overgrazing by using shift grazing; develop the experiences of reforestation; developing sense of ownership. 77

\subsubsection{Medias}

Promotion and advertisement is essential part of tourism product development in the destination. Promoting and advertising may be done by mainly in both printing and non-printing like magazines, newspaper, Radio, TVs including internets.

The media bodies at different level that owned by both government and privet has the responsibility to promote and advertise the tourism destinations in general and tourism products in particular.

\subsubsection{Educational institutions}

According to MoE, in Ethiopia there are more than 40 public universities and many collages across a country and they are working mainly in three pillars such as education, community service and research \& development, so Universities are expected to do extensive research and development in deferent issues and tourism is one of the major issue which need the intervention of such types of institution.

In case of choke mountain area mainly Debre Markos University is found there and this institution is highly recommended to do on the issue research, training and development, conservation and awareness creation about tourism industry in general and tourism product development in particular.

\subsection{Limitations of the Study and Future Research Directions}

This research manly focus on the qualitative research types but this may require some numerical data related with the challenges of tourism product development on the area. With reference to sampling techniques, this study did not utilize probability sampling techniques such as simple random sampling, systematic sampling and stratified sampling. Hence, the study applied purposive sampling techniques for the key informants and available sampling for survey visitors to collect data and draw conclusions. Because of this, the sample selected for the study may not represent the whole target populations. 
Data obtained from both Interview and FGD were analyzed together. But, interview and FGD data might need different way of analyzing methods.

As far as sources of data from published materials are concerned, the current study employed materials which do not contain the name of the publishing institution, volume and issues. This 78

Study also utilized some materials which are not up to date. This might also be a limitation in the study.

Future research works shall focus on examining the challenges of tourism products at each level of tourism stakeholder and sustainable tourism development of tourist destinations from the perspectives of foreign and domestic visitors independently. It shall also focus on repeating the current study after some years to understand whether differences were be obtained or not. Pertaining to the methodological aspects, future research shall also emphasis on both qualitative and quantitative researches.

\section{References}

Aas, C., Ladkin, A., Fletcher, J. (2005). Stakeholder collaboration and heritage management. Annals of Tourism Research, 32(1), 28-48.

Aseres SA (2015). Assessment of the Potentials Tourism Resources of Choke Mountain and its Environs, Ethiopia. Journal of Tourism and Hospitality 4: 164.

AyalewSisay. (2009). Historical Development of Travel and Tourism in Ethiopia, Addis Ababa,Ethiopia.

Ayalew A (2002) a History of Painting in East Gojjam in the Eighteenth and Nineteenth Centuries: A Study of the 'Second Gondarian' Style of Painting. Addis Ababa University, Ethiopia.

Brass, Jane L. (Ed.). (1997). Community Tourism Assessment Handbook. Western Rural Development Centre, Utah State University.

Becken S. \& Hay J. (2007) Tourism and Climate Change - risks and opportunities. Clevedon: Channel View Publications.

Cameron, R.(2009). Sequential Mixed Model Design. International Journal of Multiple Research, 3(2), 25-41.

Cooper,C.,Fletcher,J., Gilbert,D. and Wanhill, S. (1993). Tourism Principles and Practices, Pitman, London.

Darko, M. (2011). Management of World Heritage Sites.An Integrated Sustainable Marketing Approach. Arizona State University, USA. Raw Data.

Dabphet G. (2010) Tourism for development: empowering communities

DemozArefayne ,(2017) The Potential and Challenges of New Tourism Product Development and Promotional Practices of Kilte- Awlaelo Woreda Rock Hewn Churches, Tigray, Ethiopia, Bonga University, Ethiopia.

Dredge, D. (2010). Place change and tourism development conflict: Evaluating public interest. Tourism Management, 31, 104-112.

Endalkachew et al. (2018) Challenges of Tourism Destination Development in the Amhara National Regional State, Ethiopia. African Journal of Hospitality, Tourism, and Leisure,7dmu.edu.et/research-and-communityservice/choke-mountain-watershed.

Fabian Weber \& Barbara Tauter (2017). Challenges of the development of sustainable products in tourism destinations, Switzerland.

Forestry Development Center (2009). Assessment of Cancelled / Suspended / Terminated Timber License Agreement (TLA) Areas in the Philippines. FDC-UPLB-CFNR, College, Laguna

Fleming A. (1983). Ethiopia: Master Plan for the Conservation and Preservation of Cultural heritage. UNESCO Technical Report, Paris.

Freeman, R. E., (2010). Strategic management: A stakeholder approach, Cambridge.

Getnet Berhanu (2012) evaluation of Choke Mountain Range Wetland Ecosystem, East Gojjam, Amhara Region, Ethiopia: Application of Choice Experiment Valuation Method, Addis Abeba university ,Ethiopia.

Gössling, S. \& Hall, C.M. (ed) (2006a) Tourism and Global Economic Change. London: Routledge.

Gyguh (2010) New Product Development in Tourism: A Middle East Experience Rajasekharan Pillai School of Management, Manipal University.

Hall, D. \& Brown, F. (eds) (2006) Tourism and Welfare: Ethics, Responsibility and Sustained Wellbeing. Wallingford: CABI.

Hamilton, J. M., Maddison, D., \& Tol, R.S. (2005). Effects of climate change on international tourism. Climate Research, 29, 245-254.

Israel, G.D. (1992). Sampling Evidence of Extension Program Impacts, Evaluation and Organizational Development, University of Florida.

Kayat, K. (2014). Community Based Rural Tourism: A Proposed Sustainability Framework

Kauffmann, A. (2008). Challenges and Future Perspectives for Tourism Development in the Central Rift Valley, Ethiopia, Wageningen University, the Netherlands. 